\title{
Residency training in China versus the USA: puzzling the way ahead
}

\author{
Surong Hua \\ Department of General Surgery, Peking Union Medical College Hospital, Chinese Academy of Medical Sciences, Beijing, China \\ Correspondence to: Surong Hua. Department of General Surgery, Peking Union Medical College Hospital, Chinese Academy of Medical Sciences, \\ Beijing, China. Email: huasurong@sohu.com.
}

Submitted Sep 05, 2020. Accepted for publication Sep 18, 2020.

doi: 10.21037/hbsn-2020-6

View this article at: http://dx.doi.org/10.21037/hbsn-2020-6

While Chinese medical management departments may feel that the residency training program is not sufficiently rigorous, some young surgeons may find their residency in the hell mode and consider career changes. What can account for this contradiction?

As much as life and health are precious, so is residency training expensive, especially for surgical residents. Prestigious surgical educators are often paid high wages because teaching consumes much of their time that would otherwise be used for patients. Practical guidance during surgery generally requires more effort and entails extra risk for surgical teachers. Additionally, a considerable amount of funding is spent on various simulation training systems. China is still in an exploratory stage of a wellfunctioning system that can provide appropriate incentives and rewards for surgical educators. Determining how to design a teaching incentive system is beyond the scope of our discussion. An incentive system requires an enormous amount of financial support, and medical costs must ultimately be borne by society through taxation. The medical system will require more funding as a higher standard for surgeons, and thus a longer training period, are demanded from residency programs. This increasing cost will eventually be reflected in the future medical expense of the patients. However, controlling medical system funding by reducing residents' wages is not viable, as it will lead to both a decline in healthcare quality and in the quantity of practitioners.

China's national conditions determine the level of our residency training programs. The health expenditure in the United States accounts for $17.06 \%$ of their GDP, with a per capita of 9,403 US dollars, while that of China is $5.15 \%$, with a per capita of 420 US dollars; the world average is $9.90 \%$ (1). Medical students in the United States pay high tuition fees. The Accreditation Council for Graduate Medical Education (ACGME) funds residency positions throughout the country. In the United States, teaching hospitals or tertiary medical centers not only benefit from having residency programs but also gain financially from having a pool of cheap labor; losing qualification thus means losing both of these benefits. Therefore, residents in the USA can directly request proper training and handson practice, as these are their rights. However, China's health expenditures are low, and the portion allotted to medical education is even lower. In contrast to their American counterparts, teaching hospitals in Chinese residency training programs cannot receive sufficient funding. Without adequate resources, teaching surgeons lack motivation and incentive, which leads to the lower educational quality of their residency programs. Although Chinese residents pay a substantial amount of time and opportunity cost to participate in programs, they face future employment and social pressure. They are also hesitant to speak up for themselves to fight for more training opportunities, and many of them are recruited by the teaching hospital to do redundant or menial work. Lacking sufficient experience in the operating room or wards, young surgeons who graduate from these residency programs may be less competent in terms of surgical skills compared with other visiting surgeons (from tertiary hospitals or overseas) or past self-taught surgeons.

In addition to the above, China found it challenging when trying to copy the $\$ 9,403$ US residency program because it cannot afford the cost of such a program. In the 
past, it was shown that the low-cost mode of self-taught surgeons and visiting surgeons worked well in the Chinese healthcare system. A routine operation at the same level of efficacy is even faster and cheaper to access in China than in the United States. Does having low-cost, self-taught surgeons and visiting surgeons render residency programs unnecessary? When a career and technical education (CTE) can prepare students for specialized jobs in a short period of time, is undergraduate education still worthwhile? The answer seems obvious. However, an excellent surgeon does not only require the necessary surgical skills but must also possess a broad range of multidisciplinary medical knowledge, which can lay the foundation for future career development. A residency program is needed, therefore, but in a different form.

Should we consider reforming our residency program according to the US standard? If we adopt the US residency program, residents could not afford and would not be willing to pay for such high tuition fees, and the patients could not afford surgeons raised that way. Most Chinese surgeons would look for the most cost-effective and suitable training program elsewhere. Meanwhile, if the US residency program were copied minus the high-quality teaching team and the mature teach-learn system, the program would not achieve the same results as that of the US program, and would waste the time and learning opportunities of our future surgeons.

The question remains then as to what degree reform should be enacted. The medical industry in China is expanding in pace with the growth of economy and the population's medical needs, and residency programs must also keep in stride with this progress. China has a large population base and large geographical differences, and so reforms should neither be too radical nor too conservative. How to customize a residency program that is suitable for China is an indeed challenging problem.

The model of independent development of different departments within the hospital has become outmoded. In a future with an aging society, the proportion of patients with multiple system diseases will be much higher. From an all-inclusive to a specialized model, the medical system will inevitably be integrated again. The rise of multiple disciplinary teams (MDTs) in recent years is clear proof that young surgeons should lay a solid foundation during their residency training.

The rise in social wealth has led to a greater patient demand for a better medical experience. For young doctors, this rapid increase in medical demand means that high- quality doctors will be more needed in the future. In the currently limited medical budget, more funds are used for diagnosis and treatment than for teaching. Thus, for individual doctors, learning opportunities need to be acquired or created by their own enterprise.

What do you think of your residency program?

\section{Acknowledgments}

Funding: None.

\section{Footnote}

Provenance and Peer Review: This article was commissioned by the editorial office, Hepatobiliary Surgery and Nutrition. The article did not undergo external peer review.

Conflicts of Interest: The author has completed the ICMJE uniform disclosure form (available at http://dx. doi. org/10. 21037/hbsn-2020-6). The author has no conflicts of interest to declare.

Ethical Statement: The author is accountable for all aspects of the work in ensuring that questions related to the accuracy or integrity of any part of the work are appropriately investigated and resolved.

Open Access Statement: This is an Open Access article distributed in accordance with the Creative Commons Attribution-NonCommercial-NoDerivs 4.0 International License (CC BY-NC-ND 4.0), which permits the noncommercial replication and distribution of the article with the strict proviso that no changes or edits are made and the original work is properly cited (including links to both the formal publication through the relevant DOI and the license). See: https://creativecommons.org/licenses/by-nc-nd/4.0/.

\section{References}

1. World Health Organization Global Health Expenditure database. Current health expenditure (\% of GDP). Available online: https://data.worldbank.org.cn/indicator/ SH.XPD.CHEX.GD.ZS

Cite this article as: Hua S. Residency training in China versus the USA: puzzling the way ahead. HepatoBiliary Surg Nutr 2020;9(5):682-683. doi: 10.21037/hbsn-2020-6 